\title{
Front Matter: Volume 6576
}

, "Front Matter: Volume 6576," Proc. SPIE 6576, Independent Component Analyses, Wavelets, Unsupervised Nano-Biomimetic Sensors, and Neural Networks V, 657601 (9 April 2007); doi: 10.1117/12.729787

SPIE Event: Defense and Security Symposium, 2007, Orlando, Florida, United SPIE. States 


\section{PROCEEDINGS OF SPIE}

\section{Independent Component Analyses, Wavelets, Unsupervised Nano-Biomimetic Sensors, and Neural Networks $V$}

Harold H. SzU

Jack Agee

Editors

10-13 April 2007

Orlando, Florida, USA

Sponsored and Published by

SPIE-The International Society of Optical Engineering

Volume 6576

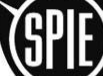

The International Society for Optical Engineering

Proceedings of SPIE-The International Society for Optical Engineering, 9780819466983, v. 6576

SPIE is an international technical society dedicated to advancing engineering and scientific applications of optical, photonic, imaging, electronic, and optoelectronic technologies. 
The papers included in this volume were part of the technical conference cited on the cover and title page. Papers were selected and subject to review by the editors and conference program committee. Some conference presentations may not be available for publication. The papers published in these proceedings reflect the work and thoughts of the authors and are published herein as submitted. The publisher is not responsible for the validity of the information or for any outcomes resulting from reliance thereon.

Please use the following format to cite material from this book:

Author(s), "Title of Paper," in Independent Component Analyses, Wavelets, Unsupervised NanoBiomimetic Sensors, and Neural Networks V, edited by Harold H. SzU, Jack Agee, Proceedings of SPIE Vol. 6576 (SPIE, Bellingham, WA, 2007) Article CID Number.

ISSN 0277-786X

ISBN 9780819466983

Published by

SPIE-The International Society for Optical Engineering

P.O. Box 10, Bellingham, Washington 98227-0010 USA

Telephone 1 360/676-3290 (Pacific Time) · Fax 1 360/647-1445

http://www.spie.org

Copyright (C) 2007, The Society of Photo-Optical Instrumentation Engineers

Copying of material in this book for internal or personal use, or for the internal or personal use of specific clients, beyond the fair use provisions granted by the U.S. Copyright Law is authorized by SPIE subject to payment of copying fees. The Transactional Reporting Service base fee for this volume is $\$ 18.00$ per article (or portion thereof), which should be paid directly to the Copyright Clearance Center (CCC), 222 Rosewood Drive, Danvers, MA 01923. Payment may also be made electronically through CCC Online at http://www.copyright.com. Other copying for republication, resale, advertising or promotion, or any form of systematic or multiple reproduction of any material in this book is prohibited except with permission in writing from the publisher. The CCC fee code is 0277 $786 \times / 07 / \$ 18.00$.

Printed in the United States of America. 


\title{
Contents
}

\author{
ix Conference Committees \\ xiii Introduction
}

SESSION 12007 UNSUPERVISED ICA AWARD

657602 Independent vector analysis for real world speech processing (Invited Paper) [6576-36]

I. Lee, T.-W. Lee, Univ. of California, San Diego (USA)

\section{SESSION 2 UNSUPERVISED APPLICATIONS IN MEDICINE}

657603 Improved denoising approach using higher-order statistics [6576-09]

S. P. Kozaitis, Florida Institute of Technology (USA)

657604 Design and implementation of a support vector machine using an optoelectronic matrixvector multiplier [6576-29]

J. Gimeno, H. Lamela, M. Jiménez, M. González, M. Ruiz-Llata, Univ. Carlos III de Madrid (Spain)

657605 Unsupervised learning with mini free energy (Invited Paper) [6576-42]

H. Szu, Howard Univ. (USA); L. Miao, H. Qi, Univ. of Tennessee (USA)

657606 Learning, entropy, free energy, an underlying commonality? (Invited Paper) [6576-48]

J. E. Gray, H. H. Szu, Naval Surface Warfare Ctr. (USA)

657607 Design of a cylindrical fiber-optic lens focusing passive dual-color IR spectra and readout (Invited Paper) [6576-53]

K. Byrd, H. SzU, Howard Univ. (USA)

Pagination: Proceedings of SPIE follow an e-First publication model, with papers published first online and then in print and on CD-ROM. Papers are published as they are submitted and meet publication criteria. A unique, consistent, permanent citation identifier (CID) number is assigned to each article at the time of the first publication. Utilization of CIDs allows articles to be fully citable as soon they are published online, and connects the same identifier to all online, print, and electronic versions of the publication.

SPIE uses a six-digit CID article numbering system in which:

- The first four digits correspond to the SPIE volume number.

- The last two digits indicate publication order within the volume using a Base 36 numbering system employing both numerals and letters. These two-number sets start with 00, 01, 02, 03, 04, 05, 06, 07, 08, 09, OA, OB ... 0Z, followed by 10-1Z, 20-2Z, etc.

The CID number appears on each page of the manuscript. The complete citation is used on the first page, and an abbreviated version on subsequent pages. 
657608 Exploratory analysis of functional MRI analysis using HSOM and HTMP [6576-23] A. Saalbach, Florida State Univ. (USA) and Bielefeld Univ. (Germany); O. Lange, A. Meyer-Baese, Florida State Univ. (USA)

657609 Singular value decomposition-based segmentation of multi-component signals [6576-14] S. Rajan, Defence Research and Development Canada-Ottawa (Canada); R. Doraiswami, Univ. of New Brunswick (Canada)

65760A Analysis of breast MRI data based on (topographic) independent and tree-dependent component analysis [6576-22]

A. Saalbach, Florida State Univ. (USA) and Bielefeld Univ. (Germany); O. Lange, Florida State Univ. (USA); T. Nattkemper, Bielefeld Univ. (Germany); A. Meyer-Baese, Florida State Univ. (USA)

65760B Multispectral MWIR image classification using filters derived from independent component analysis (Invited Paper) [6576-120]

S. Chari, C. Halford, E. Jacobs, A. Robinson, Univ. of Memphis (USA)

\section{SESSION 42007 WAVELETS PIONEER AWARD}

65760C A taste of compressed sensing (Invited Paper) [6576-37]

A. Cohen, Lab. Jacques-Louis Lions, Univ. Pierre et Marie Curie (France); W. Dahmen, RWTH Aachen (Germany); R. DeVore, Univ. of South Carolina (USA)

\section{SESSION $5 \quad$ WAVELET APPLICATIONS}

65760D Next gen wavelets down-sampling preserving statistics [6576-44]

H. Szu, Zwings, Inc. (USA); L. Miao, P. Chanyagon, M. Cader, Univ. of Tennessee (USA)

65760E Video watermarking capacity in the DWT hierarchy [6576-07]

M. Mitrea, O. Dumitru, F. Prêteux, GET/INT (France)

65760F The Rocchio classifier and second generation wavelets [6576-47]

P. H. Carter, Naval Surface Warfare Ctr. (USA)

$65760 \mathrm{G}$ Wavelet-based fusion approach using unique reconstruction approach [6576-08] M. Ovendeno, S. P. Kozaitis, Florida Institute of Technology (USA)

65760l Texture classification using wavelet preprocessing and vector quantization [6576-15] E. P. Lam, Thales Raytheon Systems (USA)

65760J Improved total variation algorithms for wavelet-based denoising [6576-02] G. R. Easley, System Planning Corp. (USA); F. Colonna, George Mason Univ. (USA) 
65760K Nanorobot assembly of carbon nanotubes for mid-IR sensor (Invited Paper) [6576-34] N. Xi, J. Zhang, Michigan State Univ. (USA); H. SzU, Office of Naval Research (USA); G. Li, Univ. of Pittsburgh (USA)

\section{NANOSCIENCE AND NANOTECHNOLOGY}

65760L Future directions of nanometrology and nanomanufacturing (Invited Paper) [6576-46]

K. W. Lyons, National Institute of Standards and Technology (USA)

\section{SESSION 7 WELLNESS ENGINEERING AWARD}

657600 Wellness engineering for better quality of life of aging baby boomer (Invited Paper) [6576-35]

H. Szu, Office of Naval Research (USA)

\section{SESSION 8 REAL WORLD DATA ANALYSIS}

65760P A plea for adaptive data analysis (Invited Paper) [6576-43]

N. E. Huang, National Central Univ. (Taiwan)

$65760 Q \quad$ Exploring pavement crack evaluation with bidimensional empirical mode decomposition [6576-13]

A. Ayenu-Prah, N. Attoh-Okine, Univ. of Delaware (USA)

65760R Noninvasive methodology for wellness baseline profiling (Invited Paper) [6576-33]

D. W.-Y. Chung, Y.-S. Tsai, S.-G. Miaou, W. H. Chang, Y.-J. Chang, S.-C. Chen, Y. Y. Hong, C. S. Chyang, Chung Yuan Christian Univ. (Taiwan); Q.-S. Chang, H.-Y. Hsu, J. Hsu, W.-C. Yao, M.-S. Hsu, Ming-Shen Hospitals at Long Tan (Taiwan); M.-C. Chen, S.-C. Lee, National Taiwan Univ. Hospital, NTU (Taiwan); C. HsU, L. Miao, K. Byrd, M. F. Choikha, X.-B. GU, P. C. Wang, Howard Univ. (USA); H. SzU, Howard Univ. (USA) and Office of Naval Research (USA)

65760S Contactless monitoring of electric fields to improve security and safety (Invited Paper) [6576-31]

H. Sidman, R. W. VanDine, DKL International (USA); T. Wong, NanoSensors, Inc. (USA)

\section{SESSION 9 AUTONOMOUS UAV AND SENSORS}

$65760 T$ Smart Altera firmware for DSP with FPGAs (Invited Paper) [6576-10]

U. Meyer-Baese, Florida State Univ. (USA); A. Vera, Univ. of New Mexico (USA); A. Meyer-Baese, Florida State Univ. (USA); M. Pattichis, Univ. of New Mexico (USA); R. Perry, Florida State Univ. (USA)

65760 FPGA wavelet processor design using language for instruction-set architectures (LISA) [6576-11]

U. Meyer-Bäse, Florida State Univ. (USA); A. Vera, The Univ. of New Mexico (USA); S. Rao, K. Lenk, Florida State Univ. (USA); M. Pattichis, The Univ. of New Mexico (USA) 
65760 3D map generation for biomimetic applications using a network of multi-static radar sensors (Invited Paper) [6576-30]

S. Kadambe, Univ. of Maryland, College Park (USA)

65760W Analog processor design for potentiometric sensor array and its applications in smart living space [6576-40]

D. W.-Y. Chung, Y.-L. Tsai, T.-T. Liu, Chung-Yuan Christian Univ. (Taiwan); C.-L. Leu, Dahan Institute of Technology (Taiwan); C.-H. Yang, Van Nung Univ. of Technology (Taiwan);

D. G. Pijanowska, W. Torbicz, Institute of Biocybernetics and Biomedical Engineering

(Poland); P. B. Grabiec, B. Jaroszewicz, Institute of Electron Technology (Poland)

65760X Neural dynamic optimization for autonomous aerial vehicle trajectory design [6576-17]

P. Xu, A. Verma, R. J. Mayer, Knowledge Based Systems, Inc. (USA)

\section{SESSION 10 SMART SENSORS}

$65760 Y$ Hardware implementation of a neural vision system based on a neural network using integrated and fire neurons [6576-28]

M. González, H. Lamela, M. Jiménez, J. Gimeno, M. Ruiz-Llata, Univ. Carlos III de Madrid (Spain)

657610 Programmed optoelectronic time-pulse coded relational processor as base element for sorting neural networks [6576-20]

V. G. Krasilenko, Open International Univ. of Human Development Ukraine (Ukraine);

V. F. Bardachenko, V.M. Glushkov Institute of Cybernetics (Ukraine); A. I. Nikolsky,

A. A. Lazarev, Open International Univ. of Human Development Ukraine (Ukraine)

657611 A weighted quadratic asymptotic analysis of cost functions used in classifier design with extensions to finite-size training sets [6576-21]

G. J. Dobeck, Naval Surface Warfare Ctr. Panama City (USA)

657612 A fault-tolerant fully adaptive routing algorithm for collaborative computing in wireless mesh networks [6576-25]

C. Liang, X.-M. Huang, Worcester Polytechnic Institute (USA); J. Ma, The MathWorks Inc. (USA)

\section{SESSION 11 SYSTEM OF ATR}

657614 Autonomous unmanned air vehicles (UAV) techniques [6576-27]

M.-K. Hsu, T. N. Lee, The George Washington Univ. (USA)

657615 An FPGA-based rapid prototyping plafform for wavelet coprocessors [6576-18]

A. Vera, Univ. of New Mexico (USA); U. Meyer-Baese, Florida State Univ. (USA); M. Pattichis, Univ. of New Mexico (USA)

\section{SESSION 12 VISION AND ATR}

657616 Arrogance analysis of several typical pattern recognition classifiers [6576-06]

C. Jing, S. Xia, W. Hu, National Univ. of Defense Technology (China) 
657617 Implicit differential analysis for cortical models [6576-49]

F. McFadden, General Dynamics Advanced Information Systems (USA); H. SzU, Howard Univ. (USA)

657619 Intellectual property protection of IP cores through high-level watermarking [6576-12]

E. Castillo, Univ. of Granada (Spain); U. Meyer-Baese, Florida State Univ. (USA); A. García, L. Parrilla, A. Lloris, Univ. of Granada (Spain)

$65761 \mathrm{~A}$ Technique of information hiding based on neural network [6576-03]

L. Xu, G. Tao, North China Institute of Science and Technology (China)

65761B Research on the technique of public watermarking system based on wavelet transform and neural network [6576-05]

L. Xu, G. Tao, North China Institute of Science and Technology (China)

65761C Carrier signal design using constrained iterative spectral deconvolution [6576-01]

A. M. Amini, Southern Univ. (USA)

Author Index 
Downloaded From: https://www.spiedigitallibrary.org/conference-proceedings-of-spie on 26 Apr 2023

Terms of Use: https://www.spiedigitallibrary.org/terms-of-use 


\title{
Conference Committees
}

\author{
Symposium Chair
}

John C. Carrano, Luminex Corporation (USA)

Symposium Cochair

Larry B. Stotts, DARPA (USA)

Program Track Chair

Andrew R. Pirich, Air Force Research Laboratory (USA)

Conference Chairs

Harold H. Szu, Office of Naval Research (USA), Howard University (USA), and Zwings Inc. (USA)

Jack Agee, Rice University (USA)

Conference Cochairs

Shoji Makino, Nippon Telegraph and Telephone Corporation (Japan) and Hokkaido University (Japan)

C. Sidney Burrus, Rice University (USA)

Award Chairs

C. Sidney Burrus, Rice University (USA)

Wen-Lee Cheng, Chung Yuan Christian University (Taiwan)

C. S. Chyang, Chung Yuan Christian University (Taiwan)

Kevin W. Lyons, National Institute of Standards and Technology (USA)

Shoji Makino, Nippon Telegraph and Telephone Corporation (Japan) and Hokkaido University (Japan)

Francisco Santiago, Naval Surface Warfare Center (USA)

Harold H. Szu, Office of Naval Research (USA), Howard University (USA), and Zwings Inc. (USA)

Award Committee

Norden E. Huang, NASA Goddard Space Flight Center (USA) and National Central University (Taiwan)

Hanseok Brian Ko, Korea University (South Korea)

G. Moon, Hallym University (South Korea)

Hyunsook Yoon, Hallym University (South Korea) 
Program Committee

Shun-ichi Amari, The Institute of Physical and Chemical Research (RIKEN) (Japan)

David G. Brown, U.S. Food and Drug Administration (USA)

Chang Wen Chen, Florida Institute of Technology (USA)

Danny Wen-Yaw Chung, Chung Yuan Christian University (Taiwan)

Andrzej S. Cichocki, The Institute of Physical and Chemical Research (RIKEN) (Japan)

Qian Du, Mississippi State University (USA)

Norden E. Huang, NASA Goddard Space Flight Center (USA) and National Central University (Taiwan)

Phillip Q. Hwang, National Imagery and Mapping Agency (USA)

Joseph Landa, BriarTek Inc. (USA)

Soo-Young Lee, Korea Advanced Institute of Science and Technology (South Korea)

William Liou, Western Michigan University (USA)

Anke Meyer-Bäse, Florida State University (USA)

Uwe H. Meyer-Bäse, Florida State University (USA)

Francesco C. Morabito, Università degli Studi di Reggio Calabria (Italy)

Erkki Oja, Helsinki University of Technology (Finland)

Dennis W. Prather, University of Delaware (USA)

Hairong Qi, The University of Tennessee (USA)

Mark J. T. Smith, Purdue University (USA)

Wim Sweldens, Lucent Technologies/Bell Laboratories (USA)

Mladen V. Wickerhauser, Washington University in St. Louis (USA)

Donald C. Wunsch II, University of Missouri/Rolla (USA)

Ning Xi, Michigan State University (USA)

Takeshi Yamakawa, Kyushu Institute of Technology (Japan)

Session Chairs

12007 Unsupervised ICA Award

Shoji Makino, Nippon Telegraph and Telephone Corporation (Japan) and Hokkaido University (Japan)

Harold H. Szu, Office of Naval Research (USA), Howard University (USA), and Zwings Inc. (USA)

2 Unsupervised Applications in Medicine

Te-Won Lee, University of California, San Diego (USA)

Harold H. Szu, Office of Naval Research (USA), Howard University (USA), and Zwings Inc. (USA)

3 Unsupervised Applications in Medicine II

Te-Won Lee, University of California, San Diego (USA)

Harold H. Szu, Office of Naval Research (USA), Howard University (USA), and Zwings Inc. (USA) 
2007 Wavelets Pioneer Award

C. Sidney Burrus, Rice University (USA)

Harold H. Szu, Office of Naval Research (USA), Howard University (USA), and Zwings Inc. (USA)

5 Wavelet Applications

Samuel P. Kozaitis, Florida Institute of Technology (USA)

Katherine J. Jones, Rice University (USA)

$6 \quad$ Nanoengineering Awards

Francisco Santiago, Naval Surface Warfare Center (USA)

Kevin W. Lyons, National Institute of Standards and Technology (USA)

$7 \quad$ Nanoscience and Nanotechnology

Francisco Santiago, Naval Surface Warfare Center (USA)

Kevin W. Lyons, National Institute of Standards and Technology (USA)

$8 \quad$ Wellness Engineering Award

Wen-Lee Cheng, Chung Yuan Christian University (Taiwan)

C. S. Chyang, Chung Yuan Christian University (Taiwan)

9 Real World Data Analysis

Norden E. Huang, NASA Goddard Space Flight Center (USA) and National Central University (Taiwan)

Gyu Moon, Hallym University (South Korea)

10 Autonomous UAV and Sensors

Shubha L. Kadambe, Office of Naval Research (USA) and University of Maryland, College Park (USA)

Rabinder N. Madan, Office of Naval Research (USA)

11 Smart Sensors

Danny Wen-Yaw Chung, Chung Yuan Christian University (Taiwan)

Ying-Yi Hong, Chung Yuan Christian University (Taiwan)

12 System of ATR

Miao Liden, TSU (USA)

Amy S. Smith-Carroll, Naval Surface Warfare Center (USA)

13 Vision and ATR

Frank E. McFadden, General Dynamics Advanced Information Systems (USA)

Shengping Xia, National University of Defense Technology (China) 
Downloaded From: https://www.spiedigitallibrary.org/conference-proceedings-of-spie on 26 Apr 2023

Terms of Use: https://www.spiedigitallibrary.org/terms-of-use 


\section{Introduction}

SPIE proceeding Volume 6576, titled Independent Component Analyses Wavelets, Unsupervised Learning, Nano-Biomimetic Sensors, and Neural Networks $\checkmark$, has a special significance during a decade-long history of several new disciplines merging together naturally, that can help us design smart sensors web for a safer and better home care system for an aging population. It involves, other than the traditional Wavelet Pioneer Award presented during the last fifteen years and Unsupervised Learning ICA Award for the last 5 years, a new category of Nanoengineering Award for the biomimetic smart nano-sensors. These sensors may be built through the translation of nano-science and nanotechnology knowhow developed throughout the last decade through the ten-billion dollar effort of National Nanotechnology Initiative. We must build the new discipline called "nanoengineering" in which the nano-robot controlled by the computer aided design (CAD) as the automated nano-manipulator, which can produce a reliable productivity beyond $25 \%$. Moreover, we have introduced another new category called the Wellness Engineering of the Year Award. The reason behind the incorporation of two more award categories is that we must immediately develop an accumulatively effective and affordable set of smart pair devices to save the exuberant expenditure for the healthcare of the aging population, which will not be otherwise sustainable when all the post-war baby boomers retire (78 millions will cost 1/5 1/4 GDP in the U.S. alone). We need household affordable effective devices for the daily sampling of wellness baseline profile to compile unsupervised learning of personnel diagnostic aids: "A stitch in time saves nine."

The selection procedure adopted for decades for a qualified recipient is identical to the Wavelet Pioneer Award and the Unsupervised Learning ICA Award. Namely, the new winners of the Nanoengineering Award and the Wellness Engineer of the Year Award will automatically assume the position of next year's chair of the selection committee for the following year's recipients, and will also participate or replace the next retired committee member as the new member of the committee to select subsequent recipients. In other words, the management of the conference shall not involve in the selection process of awardees, but rather will facilitate the information for the new recipient. This procedure of separating the honor from the management has maintained the credibility of these awards over the years.

Also, per SPIE policy, the recipients will always write a review paper for publication, give a plenary talk for an hour, chair a panel discussion for an hour, and teach a short course during the conference. This useful education process will ensure that all attendances can fully benefit from his or her presence at the conference and record in the proceedings and tutorial notes. Also, this procedure can sustain and financially support his or her travel and lodging 
expenditure. Such a quality assurance will be extended to the Nano-Engineering Award and Wellness Engineer of the Year Award in 2008.

We look forward to your advice and active participation. If you would like to contribute to a specific talk, chair a session, or recommend old or new speakers including yourself, please write the conference management.

Harold H. SzU 